\title{
Bi-Directional Regulation by Chinese Herbal Formulae to Host and Parasite for Multi-Drug Resistant Staphylococcus aureus in Humans and Rodents
}

\author{
Nobuo Yamaguchi',2, Takanao Ueyama ${ }^{3}$, Nurmuhamamt Amat ${ }^{4}$, Dilxat Yimit ${ }^{4}$, \\ Parida Hoxur5 $^{5}$, Daisuke Sakamoto ${ }^{6}$, Yuma Katoh ${ }^{2,7}$, Ikkan Watanabe ${ }^{2}$, Shan-Yu Su${ }^{8,9}$ \\ ${ }^{1}$ Department of Fundamental Research for CAM, Kanazawa Medical University, Uchinada, Japan \\ ${ }^{2}$ Ishikawa Natural Medicinal Products Research Center, Kanazawa, Japan \\ ${ }^{3}$ Department of Medicine II, Kansai Medical University, Osaka, Japan \\ ${ }^{4}$ Traditional Uighur Medicine Department, Xinjiang Medical University, Urumqi, China \\ ${ }^{5}$ Traditional Chinese Medicine Hospital, Xinjiang Medical University, Urumqi, China \\ ${ }^{6}$ Department of Chest Surgery, Kanazawa Medical University, Himi Citizen Hospital, Himi, Japan \\ ${ }^{7}$ Department of Respiratory Medicine, Tohkai Central Hospital, Gifu, Japan \\ ${ }^{8}$ Department of Chinese Medicine, China Medical University Hospital, Taichung City, Taiwan \\ ${ }^{9}$ School of Post-Baccalaureate Chinese Medicine, College of Chinese Medicine, China Medical University, \\ Taichung City, Taiwan \\ Email: serumaya@kanazawa-med.ac.jp
}

Received 5 February 2015; accepted 28 February 2015; published 3 March 2015

Copyright (C) 2015 by authors and Scientific Research Publishing Inc.

This work is licensed under the Creative Commons Attribution International License (CC BY).

http://creativecommons.org/licenses/by/4.0/

(c) (i) Open Access

\section{Abstract}

A decline in the immunopotential of the host plays acritical factor(s) in the occurrence of infections with methicillin-resistant Staphylococcus aureus (MRSA) or microorganisms by opportunistic infection. In such an infection, no way out for therapeutic concept, therefore bi-directional trial was the final choice. So we selected aformula, Dang Gui Liu Huang Tang (dLHT), which could both augmentimmune factorsin host and exert bacteriostatic effect. We sought to break through the epidemic by MRSA especially in elderly patient, by the fundamental and clinical trial by employing minor TCM, characterizing bidirectional ability of the decoction by western methods. Animal Experiment: Mitomycin-C (MMC)-treated mice with or without the infection of MRSA were made. The experimental design was made up to examine the bacteriostatic action as well as the immunopotentiating bias of the promising Chinese herbal medicine, dLHT, which was first proved for its immune potentiating activities as well as their sensitivity to antibiotics, but not direct aseptic effect was clear for MRSA. Both basic and clinical data showed that this formula was effective on re- 
pelling from the infectious focus after the treatment of MRSA infection. After the administration of dLHT, the number of white blood cells in MMC-treated mice recovered to $80 \%$ of the normal level. In addition, the phagocytic activity of macrophages increased to $70 \%$ in the dLHT-treated group, while that of the non-treated group was only $20 \%$. The bactericidal activity also recovered to the level close to the normal value by dLHT. The ratio of neutrophils in the dLHT-administered group increased to $2.2 \%$ (normal mice, $2.6 \%$ ), whereas that in the non-terated group was only $0.5 \%$. The bacterial count in the liver of MRSA-challenged mice reached the peak at six hours after the challenge in both dLHT-treated and non-treated mice. However, the number of bacteria in dLHT group was much greater than that in the non-treated group. The bacterial count in the blood showed an increase 12 and 24 hours after the challenge. Even 24 hours after the challenge, a significant number of bacteria existed in the blood of dLHT-administered group, whereas only a small number of bacteria detectable 6 hours after the challenge and the number gradually decreased thereafter in the dLHT-administered group. MRSA-challenged MMC-treated mice were treated by dLHT, vancomycin, or dLHT and vancomycin. All of non-treated mice died 8 days after the MRSA challenge, whereas the survival rates were $60 \%$ after dLHT treatment, $40 \%$ after vancomycin treatment, and $80 \%$ after dLHT and vancomycin treatment. All of MMC-treated mice, to which the phagocytic cells prepared from MMC-treated mice with dLHT administration had adoptively been transferred, survived from MRSA challenge. On the other hand, the survival rate of MMC-treated mice, to which the lymphocytes prepared from the same mice had adoptively been transferred, was $40 \%$. Clinical Trial: All cases with dLHT treatment showed negative culture results for MRSA after the dLHT administration. The culture generally became negative less than $\mathbf{5 0}$ days after the initial administration, whereas one control case needed more than 100 days and the other was dead of the infection. One representative case, who was a 78-year-old woman suffering from hypertension, atrial fibrillation, and cerebral bleeding in the right occipital lobe, infected with MRSA during the antibiotic therapy for Streptococcus pneumoniae. The antibiotic therapy was halted and the dLHT administration started. Three weeks later, the culture result became negative. In addition, serum protein and albumin values also returned to the level that they had had before the infection of MRSA.

\section{Keywords}

Drug Sensitivity, Multiple Resistance, Dang Gui Liu Huang Tang, MRSA, Nosocomical Infection, Host Immunity

\section{Introduction}

The decline in the immunopotential of the host plays an essential role in the occurrence of infections even by low pathogenic bacteria, methicilline-resistant Staphylococcus aureus (MRSA) or pseudomonas. There are two primary systems, innate immunity and adaptive immunity. Despite these defense systems, the overwhelming problems of possessing these dual systems, the innate and adaptive does not seem to guard or even prevent the development of one internal threat to survival. However, every individual exposes to the list of immunodeficiency in daily life with both internal and externals [1]-[10]. The factors that influence the acquired immune activity are systemic metabolic disorders such as diabetes, malnutrition, extreme exhaustion, extensive stress, aging and medical side effects [1]-[10]. So we have to select appropriate menu to regulate immune function through leukocyte storage. The menu had been summarized and listed as CAM: complementary and alternative medicine [11]-[18]. The use of the menu in conjunction with exercise recipe is in a quandary due to the lack of information concerning these cross-interactions among general public and a lack in information among the health professionals with a potentially significant health scale.

In other words, there are no tentative scales for evaluating the intense of exercise for each patient. A propose of this study is to suggest the best tailored scale for evaluating the intense of menu. For this purpose, we sought to set up a mouse model in which mice were infected with MRSA and treated with mitomycin-C (MMC) to examine the bacteriostatic and anti-inflammatory actions as well as the immuno-competent actions of the prom- 
ising Chinese herbal medicine, Dang Gui Liu Huang Tang (dLHT). dLHT was also administered to patients who were infected with MRSA. Both animal and clinical experiments compared dLHT with standard hemopoietic herbal decoction in the MRSA infection system.

\section{Experimental Design}

\subsection{Experimental Mice}

Eight-week-old male C57BL/6J mice (Sankyo Animal Laboratory Inc.) were kept at clear animal housing at specific pathogen free condition (SPF) with a room temperature of $24^{\circ} \mathrm{C} \pm 1^{\circ} \mathrm{C}$ and a humidity of $60 \%$. The water and mice food were freely accessed.

\subsection{Experimental Animal Model}

In the animal model of immuno-competency reduction, mice were injected with MMC ( $5 \mathrm{mg} / \mathrm{kg}$ ) to inhibit the bone marrow. An extract of dLHT, which was freezed and dried, was administered orally at a dosage of 1 $\mathrm{g} / \mathrm{kg} /$ day for five consecutive days. The white cell count, the ability of the macrophages to migrate, and phagocytosis of MRSA clinical were examined. The bacteria count in the liver reached the peak six hours after the injection. In the combined treatment group with dLHT + antibiotics, the number of bacteria decreased markedly. Moreover, in the joint treatment group, the blood bacteria number increase 6 hours and 12 hours after treatment, and a great number of bacteria lasted after 24 hours. On the other hand, there was no increasing in bacteria count in the treatment group. After introducing MMC, dLHT was administered orally for five days. Two days after the last administration, spleen cells were removed, and phagocytic cells and lymphocytes were passively transferred into recipient mice whose bone marrows were inhibited. MRSA was injected into the peritoneal cavity of the mice thereafter, and the survival rate was observed. After two weeks, all the mice which were injected with phagocytes survived longer, but the survival rate in the group that were injected with lymphocytes was only $40 \%$ (Figure 1).

\subsubsection{Survey of White Blood Cell after dLHT Administration}

The bone marrow suppressed mice were administered herbal decoction dLHT $1 \mathrm{~g} / \mathrm{kg}$ dairy for 5 times and after 2 weeks later, their blood were withdrawn from their tail vain. Then, leukocytes were counted the using BürkerTürk solution.

\subsubsection{Survey of Leukocyte Subsets after dLHT Administration}

The bone marrow suppressed mice were administered herbal decoction dLHT $1 \mathrm{~g} / \mathrm{kg}$ dairy for 5 days, and after 2 weeks, their blood was withdrawn from their tail vain. Then, granulocytes and lymphocytes were counted using Bürker-Türk solution.

\subsubsection{Survey of Macrophage Activity, Migration after dLHT Administration}

Cells of peritoneal exudates were collect from the peritoneal cavity of bone marrow. The cell suspension was purified by adherent technique for phagocyte, which resulted in over $95 \%$ of cells being phagocytes. The purified cells were adjusted to $1 \times 10^{4} \mathrm{cell} / \mathrm{ml}$ and loaded at the upper chamber of Boyden chamber for test migration. Human serum was incubated at $56^{\circ} \mathrm{C}$ for $30 \mathrm{~min}$ for the chemotactic agent for mouse phagocyte [19]-[22].

\subsubsection{Macrophage Activity, Phagocytosis}

The same cells suspension was purified by adherent technique for phagocyte, which resulted in over $95 \%$ of cells being phagocytes. The purified cells were adjusted to $1 \times 10^{4} \mathrm{cell} / \mathrm{cm}^{2}$ and mixed with latex beads which are $5 \mu \mathrm{m}$ in granule with fluorescence isochianate. After $90 \mathrm{~min}$ of incubation, the remained granules were washed out from the glass slide and counting was done automatically by ACAS system, which made digital presentation, to evaluate phagocytic cell in number and their ability to catch up the latex beads (Adherent Cell Activity Evaluating System, Shimazu, Kyoto, Japan).

\subsubsection{Recovery of Macrophage Activity, Target Cell Killing}

The same phagocytes suspension was purified by adherent technique for phagocyte, which resulted in over 95\% 


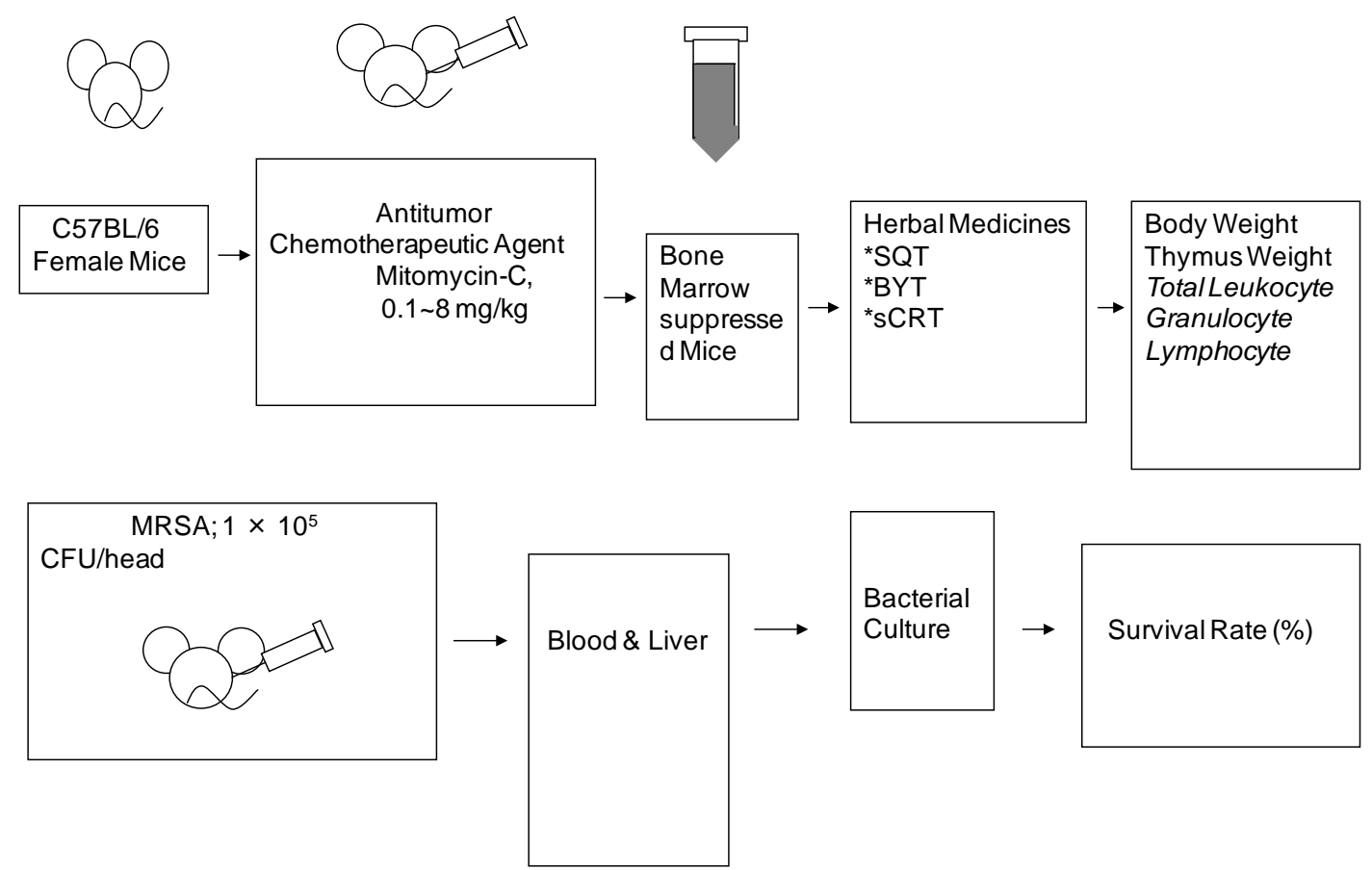

\begin{abstract}
Figure 1. Experimental design was dialoged in the figure. 8-week-old C57BL/6 female mice were prepared as experimentally bone marrow suppressed animals. Herbal decoctions dLHT (500 mg/kg/day) were administered just after MMC injection. After one month later of TCM administration, each group of mice were server for each experiment. For the infectious experiment, the mice were challenged with $1 \times 10^{6}$ of MRSA via peritoneal. Then the number of MRSA in the organ and survival rate were followed up to two weeks.
\end{abstract}

of cells being phagocytes. The purified cells were adjusted to $1 \times 10^{5} \mathrm{cell} / \mathrm{ml}$ and the macrophage migration, the phagocytic activity, and the bactericidal activity were examined by the Boyden chamber method, by the phagocytosis of sheep blood cells, and by the nitroblue tetrazolium (NBT) reduction test [23]-[27].

\title{
2.3. Recovery of Lymphocyte Activity, Antibody Secreting Cell
}

The bone marrow suppressed mice were administered herbal decoction dLHT and BYT $8 \mathrm{~g} / \mathrm{kg}$ dairy for 10 times. After 2 weeks, mice were immunized with sheep red blood cells, $\left(2 \times 10^{8} /\right.$ mouse $)$ intraperitoneally. Five days later, their spleen cells were collected and plague-forming cells (PFC) were develop and tested the ability of IgM and IgG antibody production using the method reported by Jerne and Nordin [28] [29].

\subsection{Effects on Drug Sensitivity}

So as to test the effect of herbal decoction dLHT on the drug sensitivities of multi-drug-resistant bacteria, dLHT were directory co-cultured with the each bacterium. The strains of clinical origin were $H$. influluenzae I-105, $H$. influluenzae I-147, E. coli ML 4901/Rms212, E. coli ML 4901/Rms213, E. coli ML 4901/Rte16, E. coli ML. 4901/Rms149, and P. aeruginosa PAO0214/pMG26. Each bacterium was co-cultured with either $3 \mathrm{mg} / \mathrm{ml}$ or 30 $\mathrm{mg} / \mathrm{ml}$ of dLHT. The bacteria were co-cultured with or without dLHT and amino benzylpenicillin. After 120 min of culture at $37^{\circ} \mathrm{C}$, remained $\mathrm{ABPC}$ were estimated.

\subsection{Experimental Infection by MRSA}

Eight-week-old male C57BL/6J mice were injected with MMC at a dosage of $5 \mathrm{mg} / \mathrm{kg}$ to inhibit the bone marrow, thus creating a mouse model with the reduced immunopotential. The decoction of dLHT was administered orally at a dosage of $1 \mathrm{~g} / \mathrm{kg} /$ day for five consecutive days, with or without a intraperitoneal injection of vancomycin $(10 \mathrm{mg} / \mathrm{kg})$ per day in the combined group for herbal medicine and antibiotics. For the infection of MRSA, $5 \times 10^{8} \mathrm{CFU}$ were injected intraperitoneally, and their survival were followed up for 4 weeks. 


\subsubsection{Kinetics of Intra-Organ Number of Bacteria}

Eight-week-old male C57BL/6J mice were injected with MMC at a dosage of $5 \mathrm{mg} / \mathrm{kg}$ to inhibit the bone marrow, thus creating a mouse model with the reduced immunopotential. The decoction of dLHT was administered orally at a dosage of $500 \mathrm{mg} / \mathrm{kg} /$ day for five consecutive days, and $10 \mathrm{mg} / \mathrm{kg}$ of vancomycin was injected intraperitoneally once a day in the combined-treatment group for herbal medicine and antibiotics. To induce the infection of MRSA, $1 \times 10^{9}$ or $5 \times 10^{8}$ cells were injected intraperitoneally. Each 5 days, mice were sacrificed to check the intra-bacterial number/bacterial clearance. Their blood and liver were harvested to test the number of bacteria. For this experiment, their liver was homogenized by Teflon homogenizer at $100 \mathrm{rpm} /$ one minute in the ice chilled basket. Then cultured by agar plate made by BHI medium (Nissui Co Ltd., Tokyo).

\subsubsection{Kinetics of Survival Curb in Mice}

After preparing reduced immunopotential mice model, the decoction of dLHT was administered orally at a dosage of $500 \mathrm{mg} / \mathrm{kg} /$ day for five consecutive days, and 10 days later their phagocyte and lymphocyte were separated. Then they were intraperitoneally challenged with $5 \times 10^{8}$ cells of MRSA. The survival was followed up for 4 weeks.

\subsubsection{Adoptive Transfer Experiment for Identify the Critical Cell for Augment against MRSA Infection}

The immune-suppressed C57BL/6J mice were administered the extract of dLHT orally at a dosage of 500 $\mathrm{mg} / \mathrm{kg} /$ day for five consecutive days. Ten days later their phagocyte and lymphocyte were separated. Then the mice were adoptively injected either phagocyte or lymphocyte $\left(1 \times 10^{5}\right.$ cell/ head $)$. Then they were challenged with MRSA, $5 \times 10^{8}$ cells intraperitoneally, and their survival was followed up to 4 weeks.

\subsection{Statistical Analysis}

Data are expressed as means \pm standard deviations. The association between the baseline and changes after the treatment of hemopoitic formula were analyzed in each individual using a one-tailed analysis of variance. A $P$ value less than 0.05 was considered to be statistically significant.

\subsection{Clinical Trial in Infection Control Bed Side}

Six elderly MRSA-infected patients, whose age ranged from 78 to 91 years, were selected and provided written informed consent. This clinical trial was approved by ethics committee in Kanazawa Medical University. Four patients were administered orally with an extract of dLHT at a dosage of $5.25 \mathrm{~g} /$ day. The clinical findings and laboratory results were observed continuously. Blood test and bacterial check were routine for inpatients in Kanazawa Medical University Hospital.

\section{Results}

\subsection{Recovery of White Blood Cell by dLHT}

The peripheral blood leukocytes were reduced to $20 \%$ in bone marrow-suppressed mice two weeks after MMC injection. The leukocyte count recovered to $57.1 \%$ of baseline in the dLHT group, 14 days after administration of the herbal decoction of dLHT at a dose of $1 \mathrm{~g} / \mathrm{kg} /$ day for 5 days (Figure 2).

\subsection{Recovery of Leukocyte Subsets}

The bone marrow-suppressed mice were administered herbal decoction dLHT $1 \mathrm{~g} / \mathrm{kg} / \mathrm{day}$ for 10 days. One week later, levels of lymphocyte, granulocyte, and monocyte in the peripheral blood from the tail vein were counted using flow cytometry. MMC, at a dosage of $5 \mathrm{mg} / \mathrm{kg}$, decreased the level of granulocyte. However, administered herbal decoction dLHT recover the leukocyte proportion almost to the level of normal control (Table 1).

\subsubsection{Recovery of Macrophage Activity, Migration}

The bone marrow-suppressed mice were administered herbal decoction of dLHT at $1 \mathrm{~g} / \mathrm{kg} /$ day for 5 days, and 1 week later, cells in peritoneal exudates were collected from peritoneal cavity. The cell suspension was purified 


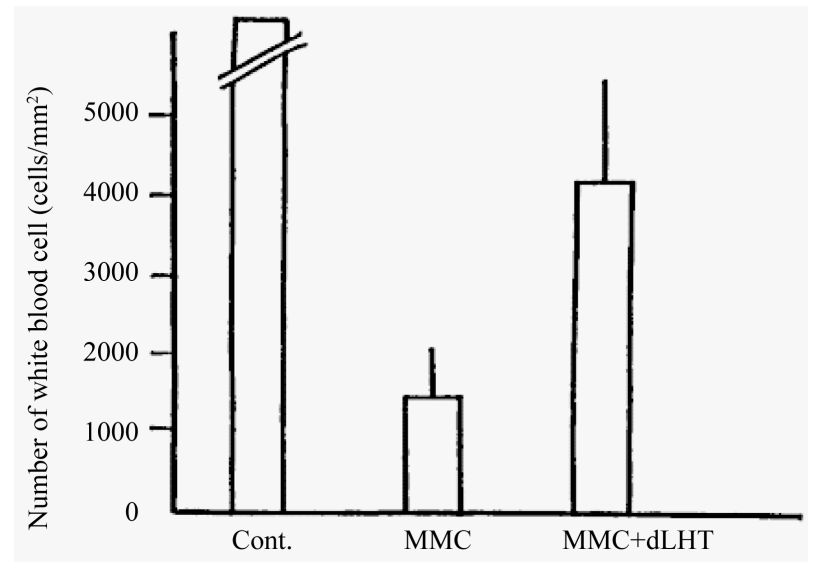

Figure 2. The capacity of dLHT on total white blood cell recovery. After the dLHT administration for 2 weeks. the peripheral blood were collected from the tail vain and counted by Bürkel-Türk counter. Data are expressed as the means $\pm \mathrm{SE}$. ${ }^{*} P$ $<0.01$, MMC versus MMC + dLHT group.

Table 1. Flow cytometric analysis of white blood cell subsets in mice.

\begin{tabular}{|c|c|c|c|}
\hline & Control $^{\mathrm{a}}$ & $\mathrm{MMC}^{\mathrm{b}}$ & $\mathrm{MMC}+\mathrm{dLHT}$ \\
\hline Lymphocyte & 58.9 & 65.0 & 54.5 \\
\hline Granulocyte & 2.6 & 0.5 & 2.2 \\
\hline Monocyte & 4.9 & 6.4 & $5.8(\%)$ \\
\hline
\end{tabular}

${ }^{\mathrm{a}}$ Normal mice; ${ }^{\mathrm{b}}$ MitomycinC (MMC)-treated mice; ${ }^{\mathrm{c}} \mathrm{MMC}$-treated mice with dLHT administration.

by adherent technique for phagocyte, which resulted in over 95\% of cells being phagocytes. The purified cells were adjusted to $1 \times 10^{6} \mathrm{cell} / \mathrm{ml}$ and loaded at the upper chamber of Boyden chamber for test migration. Human serum that has been treated at $56^{\circ} \mathrm{C}$ for 30 min was used as the chemotactic agent for mouse phagocytes. MMC treatment brought depression of migration activity $(P<0.05)$, while dLHT administration increase their migration to $90 \%$ as compared to the normal control (Figure 3 ).

\subsubsection{Recovery of Macrophage Activity, Phagocytosis by dLHT}

The cell suspension was purified by adherent technique for phagocyte, which resulted in over 95\% of cells being phagocytes. The purified cells were adjusted to $1 \times 10^{4}$ cell $/ \mathrm{cm}^{2}$ and mixed with latex beads 5 um in granule with fluorescence isocyanate. After incubated for 90 minutes, remained granule were washed out from the glass slide and counting automatically by ACAS system. The phagocytic activity of MMC-treated mice was clearly depressed both in number and function (Figures 4(a)-(d)).

\subsubsection{Recovery of Macrophage Activity, Killing}

The bone marrow suppressed mice were administered herbal decoction dLHT $1 \mathrm{~g} / \mathrm{kg} / \mathrm{day}$ for 10 days. One week later, cells in peritoneal exudates were collected from the peritoneal cavity. The cell suspension was purified by adherent technique for phagocyte, which resulted in over 95\% of cells being phagocytes. The purified cells were adjusted to $1 \times 10^{6} \mathrm{cell} / \mathrm{ml}$ to perform the nitroblue tetrazolium (NBT) reduction test. Activity of macrophage was decreased significantly in MMC-treated mice, whereas, dHLT treatment recovered their activity to normal level (Figure 5).

\subsection{Recovery of Lymphocyte Activity, Antibody Secreting Cell}

The bone marrow suppressed mice were administered herbal decoction dLHT and BYT 8 g/kg/day for 10 days 


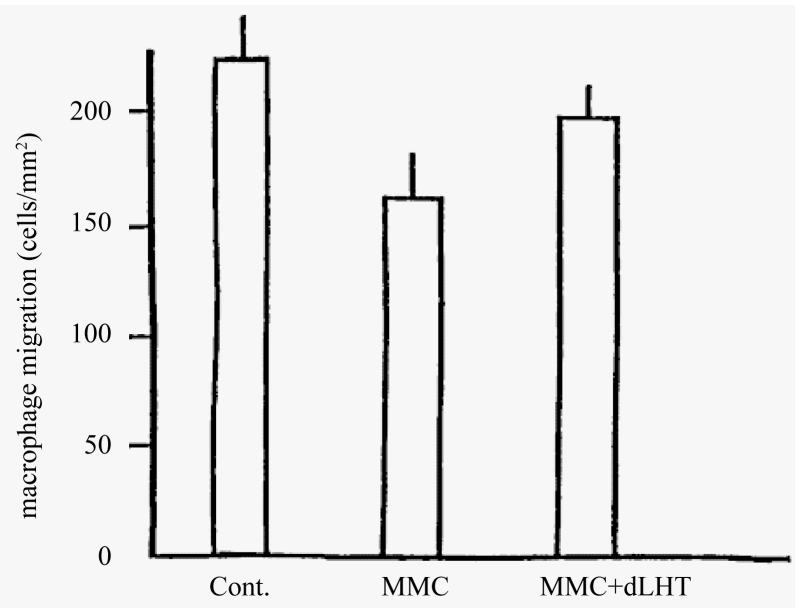

Figure 3. The effect on macrophage migration by dLHT after administrating MMC. The procedure of treatment was the same as in Figure 2. The macrophage migration capacity was detected by millipore membrane method separated by $0.25 \mu \mathrm{m}$ in diameter. Data are expressed as the means $\pm \mathrm{SE}$. ${ }^{*} P<0.05$, MMC versus MMC + dLHT group.

as positive control. Two weeks later, mice were immunized with sheep red blood cells ( $2 \times 10^{8} /$ mouse) intraperitoneally. Four and six days later, their plague-forming cells (PFC) were developed and antibody producing ability for IgM and IgG was tested by the method reported by Jerne and Nordin [28] [29]. In this mice system, MMC did not reduced the antibody forming cell in statically significant level. The tendency was the same as shown in the former section (Figure 6).

\subsection{Effects on Drug Sensitivity}

So as to test the effect of herbal decoction dHLT on the drug sensitivities of multidrug-sensitive bacteria MRSA, dHLT were directory co-cultured with the bacteria. The strains of clinical origin were $H$. influluenzae I-105, $H$. influluenzae I-147, E. coli ML 4901/Rms212, E. coli ML 4901/Rms213, E. coli ML 4901/Rte16, E. coli ML 4901/Rms149, P. aeruginosa PAO0214/pMG26. Each bacterium was co-cultured with either $3 \mathrm{mg} / \mathrm{ml}$ or 30 $\mathrm{mg} / \mathrm{ml}$ with dLHT in the presence of amino benzyl penicillin. After the co-culture with herbal decoction, and multi-resistant bacterial strains turned to sensitive at least for amino benzyle penicillin. Moreover, the relative inhibition was dose-dependent to the concentration of dLHT (Table 2).

\subsubsection{Effects of dLHT on Survival Rate in MRSA-Infected Mice}

The infection experiment was designed to integrate with the above results, exhibiting the augmentation of each component of host defense factors. Eight-week-old male C57BL/6J mice were injected with MMC at a dosage of $5 \mathrm{mg} / \mathrm{kg}$ to inhibit the bone marrow, thus a mouse model with the reduced immunopotential was created. The decoction of dLHT were administered orally at a dosage of $1 \mathrm{~g} / \mathrm{kg} /$ day for five consecutive days, and $10 \mathrm{mg} / \mathrm{kg}$ of vancomycin was injected intraperitoneally once a day for the combined-treatment group of herbal medicine and antibiotics. For the infection of MRSA, $1 \times 10^{9}$ or $5 \times 10^{8}$ bacteria were injected intraperitoneally, and their survival were followed up to 4 weeks. Figure 7 shows that the antibiotics plus dLHT group survived much longer than groups of dLHT alone and antibiotics alone.

\subsubsection{Adoptive Transfer Experiment for Identify the Critical Point for Augment against MRSA Infection}

The total estimation of host augmentation, adoptive transfer experiment was performed to identify the factor of activated site by dLHT. Eight-week-old male C57BL/6J mice were injected with MMC at a dosage of $5 \mathrm{mg} / \mathrm{kg}$ to inhibit the bone marrow, to create a mouse model of reduced immunopotential. An extract of dLHT in powder form was administered orally at a dosage of $500 \mathrm{mg} / \mathrm{kg} /$ day for five consecutive days. Ten days later their 


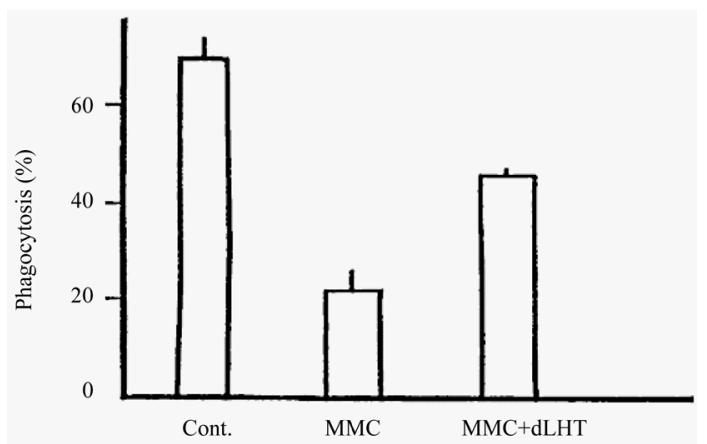

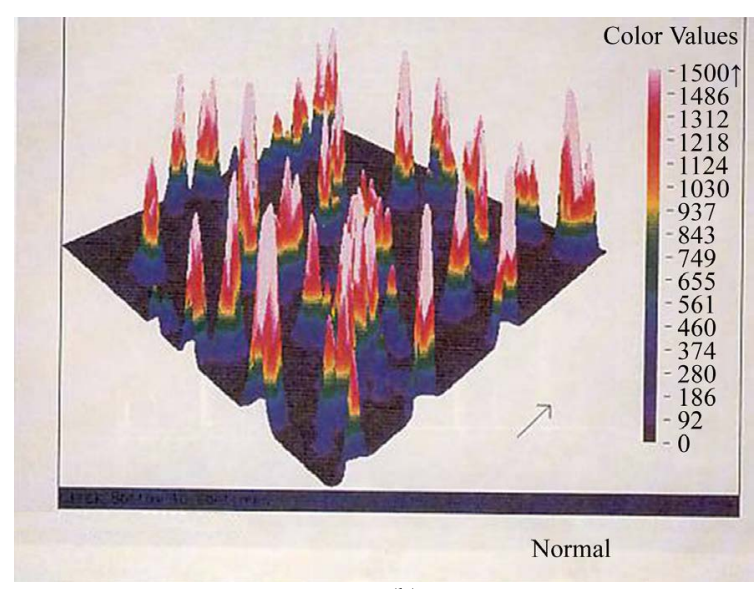

(b)

(a)

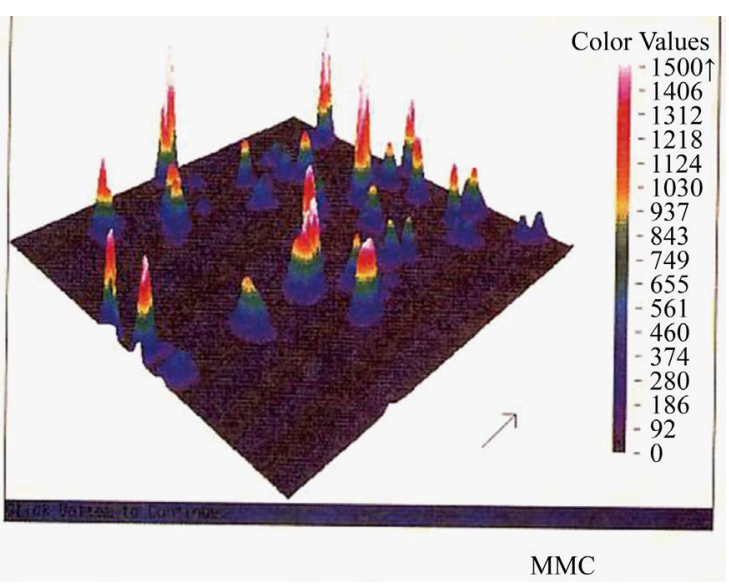

(c)

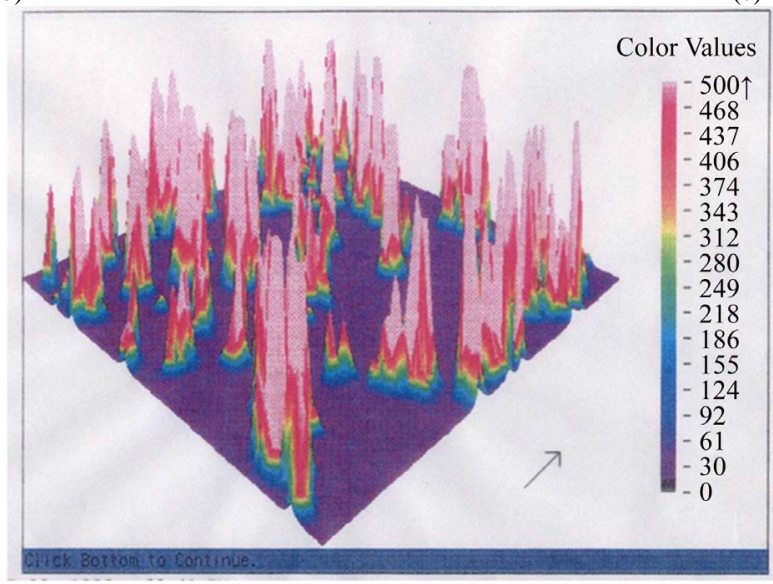

MMC+dLHT

(d)

Figure 4. (a) A classical presentation of macrophagephagocytosis agaist microorganism by dLHT after administrating MMC. The procedure of treatment was the same in Figure 2. The macrophage migration capacity in Normal control was detected by computer analysis, ACAS. Data are expressed as the means $\pm \mathrm{SE}$. ${ }^{*} P<0.01$, MMC versus MMC + dLHT group; (b) CG presentation for the effect on macrophage phagocytosis against latex beads by normal mice. Cells from peritoneal exudates were collect from the peritoneal cavity. The cell suspension was purified by adherent technique for phagocyte, which resulted in over $95 \%$ of cells being phagocytes. The purified cells were adjusted to $1 \times 10^{4} \mathrm{cell} / \mathrm{ml}$ in the slass slide. The procedure of treatment was the same in Figure 2. The macrophage phagocytosis capacity after MMC administration was detected by computer analysis, by ACAS; (c) CG presentation for the effect on macrophage phagocytosis against latex beads after administrating MMC. The procedure of treatment was the same in Figure 2. The macrophage migration capacity was detected by computer analysis, ACAS. The data was shown from MMC-treated mice; (d) CG presentation for the effect on macrophage phagocytosis against latex beads by dHLT after administrating MMC. The procedure of treatment was the same in Figure 2. The macrophage migration capacity was detected by computer analysis, ACAS. The data was shown from MMC-treated and dLHLT rescued mice. 


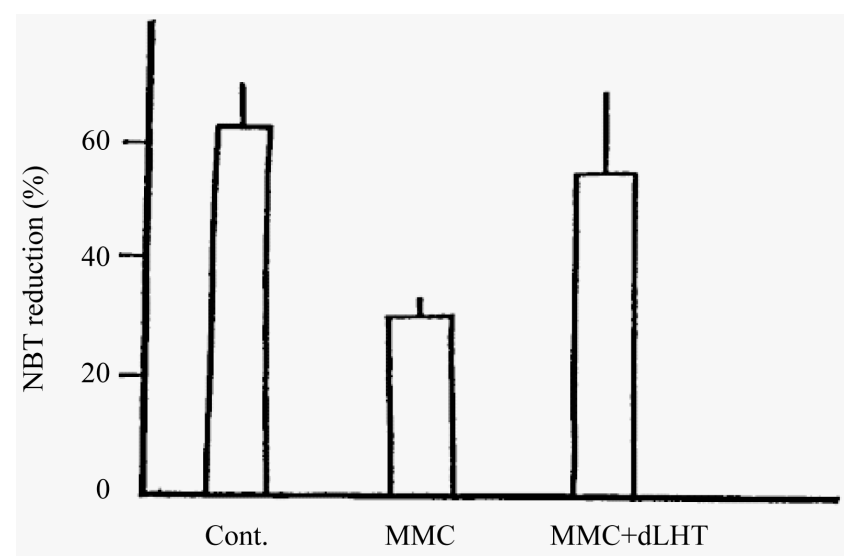

Figure 5. The effect on macrophage killing activity revealed with NBT reduction test by dHLT after administrating MMC. The procedur of treatment was the same in Figure 2, except that the killing activity was detected by Nitro-blue Tetrazolium. Data are expressed as the means $\pm \mathrm{SE} .{ }^{*} P<0.001$, MMC versus MMC + dLHT group.
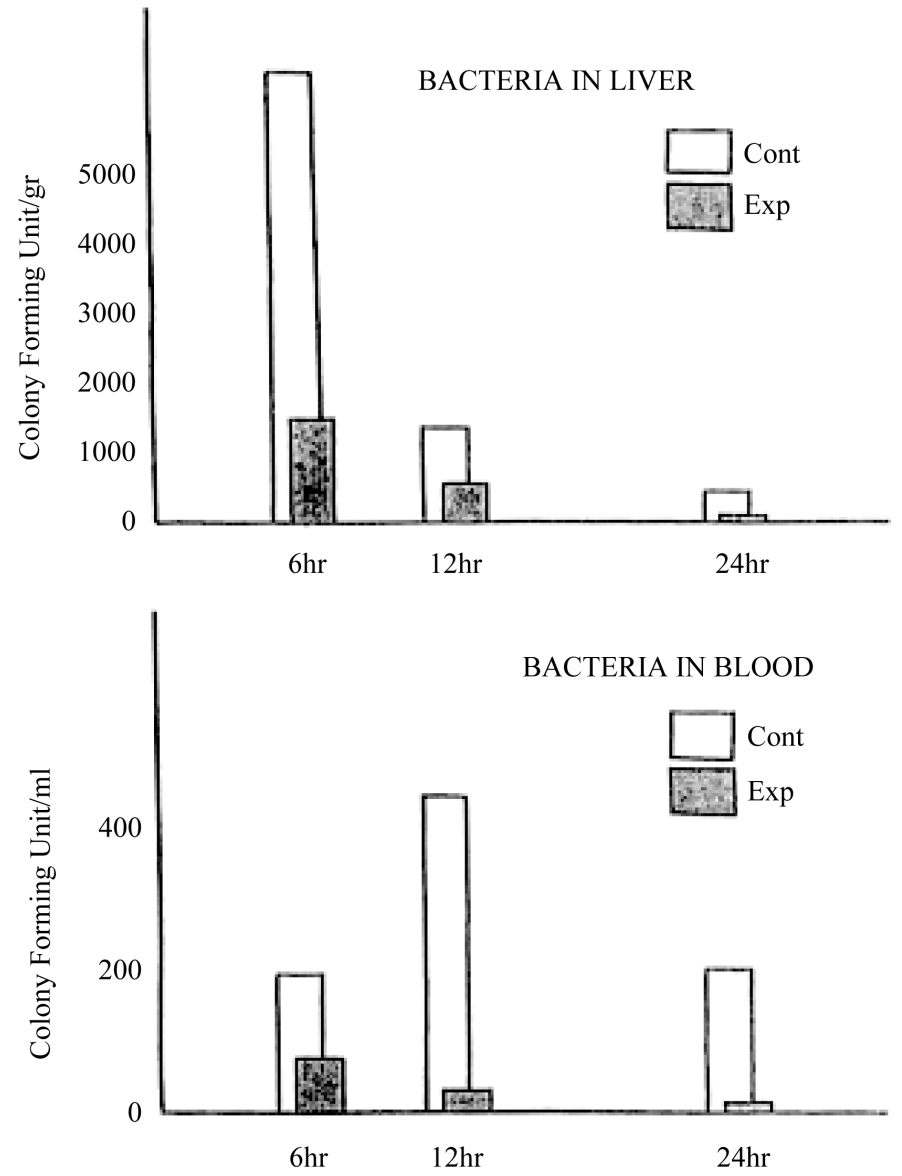

Figure 6. The infection test was tried to express number of micro organisms in each lymphoid organ. The number of MRSA counting in the organ that experimentally infected by $5 \times 10^{6}$ of microorganisms. Data are expressed as the means $\pm \mathrm{SE} .{ }^{*} P<0.001$, MMC versus MMC + dLHT group. 
Table 2. Effect on drug sensitivity by dHLT to multi \& high dose resistant clinical strain of bacteria.

\begin{tabular}{|c|c|c|c|c|c|c|c|}
\hline \multirow{3}{*}{ Enzyme } & \multirow{3}{*}{ Class } & \multicolumn{6}{|c|}{$\%$ Inhibition of penicillinase } \\
\hline & & \multicolumn{2}{|c|}{ dHLT (mg/ml) } & \multicolumn{2}{|c|}{ SQT (mg/ml) } & \multicolumn{2}{|c|}{ BYT (mg/ml) } \\
\hline & & 30 & 3 & 30 & 3 & 30 & 3 \\
\hline H. influenza I -105 & $*$ & $83.5 \pm 11.3^{* * *}$ & $3.9 \pm 1.6$ & $94.7 \pm 5.7$ & $1.5 \pm 1.4$ & $20.1 \pm 3.2$ & - \\
\hline H. influenza I -147 & * & $24.9 \pm 5.4$ & $--^{* * *}$ & $57.7 \pm 7.4$ & - & - & - \\
\hline E. coil ML4901/Rms212 & Type I & $30 \pm 12$ & $11 \pm 6$ & $107 \pm 9$ & $13 \pm 3$ & $29 \pm 8$ & $11 \pm 4$ \\
\hline E. coil ML4901/Rms213 & Type II & $85 \pm 7$ & - & $100 \pm 24$ & $31 \pm 10$ & $104 \pm 8$ & - \\
\hline E. coil ML4901/Rte16 & Type III & $73 \pm 9$ & $5 \pm 3$ & $97 \pm 27$ & $34 \pm 9$ & $100 \pm 9$ & $4 \pm 3$ \\
\hline E. coil ML4901/Rms149 & Type IV & $40 \pm 9$ & - & $94 \pm 32$ & - & $59 \pm 13$ & - \\
\hline P. aeruginosa $\mathrm{PAO} 2142 \mathrm{RP}^{\mathrm{r}} / \mathrm{Pmg} 26$ & * & $104 \pm 3$ & $13 \pm 3$ & $103 \pm 12$ & $47 \pm 5$ & $103 \pm 18$ & $5 \pm 4$ \\
\hline
\end{tabular}

*Not classified; ${ }^{* *}$ Results are an arithmetic mean from three determinations \pm standard deviation; ${ }^{* * * *}$ Not inhibited.

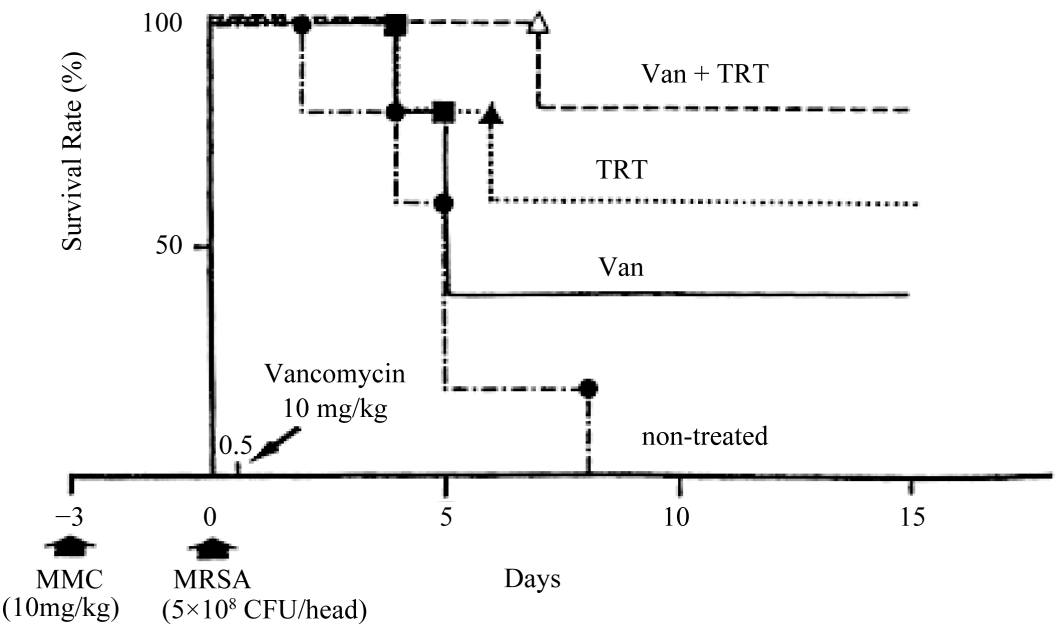

Figure 7. The experimental infection test. The test were performed by the mice divided into 4 group. The groups were consisted by normal, MMC-treated, MMCtreated + dHLT, MMC-treated + dLHT plus chemotherapeutic agency vancomycin. Each survival was followed up to six week.

phagocyte and lymphocyte were separated. Then the mice were adoptively injected either phagocyte or lymphocyte $\left(1 \times 10^{5}\right.$ cell/ head). Then they were challenged intraperitoneally with $5 \times 10^{8}$ cells of MRSA. Their survival was followed up until the fourth week. The survival rate of the group that was transferred with phagocytic cell was kept $100 \%$ during the two weeks after MRSA challenge. After the administration of dLHT, the number of white blood cells in MMC-treated mice was increase to $80 \%$ of that of the control group. In addition, the relative phagocytic activity of macrophages increased to $50 \%$ of that of the control group, while that of non-treated group was only 20\% (Figure 8). The bactericidal activity also recovered to the level close to the normal value The ratio in neutrophils in dLHT administered MMC-treated group increased to 2.2\% (normal mice, 2.6\%), whereas that in MMC-treated group was only $0.5 \%$. The bacteria count in the liver of MRSA-challenged mice with and without dLHT administration peaked six hours after the challenge. However, the number of bacteria in the group with dLHT administration was much greater than that of the group without dLHT administration. The bacteria count in the blood showed an increase at the 12th and 24th hours after the challenge. Even 24 hours after MRSA challenge, a significant number of bacteria remained in the blood of the group without dLHT administration, whereas only a small number of cells were detected 6 hours after the challenge, and the bacterial number was gradually decreased thereafter in the group of dLHT administration (Figure 8). MRSA-challenged MMC-treated mice were treated by dLHT, vancomycin, or dLHT combined with vancomycin. All of the nontreated mice died eight days after the MRSA challenge, whereas the survival rates in the dLHT group was $60 \%$, 


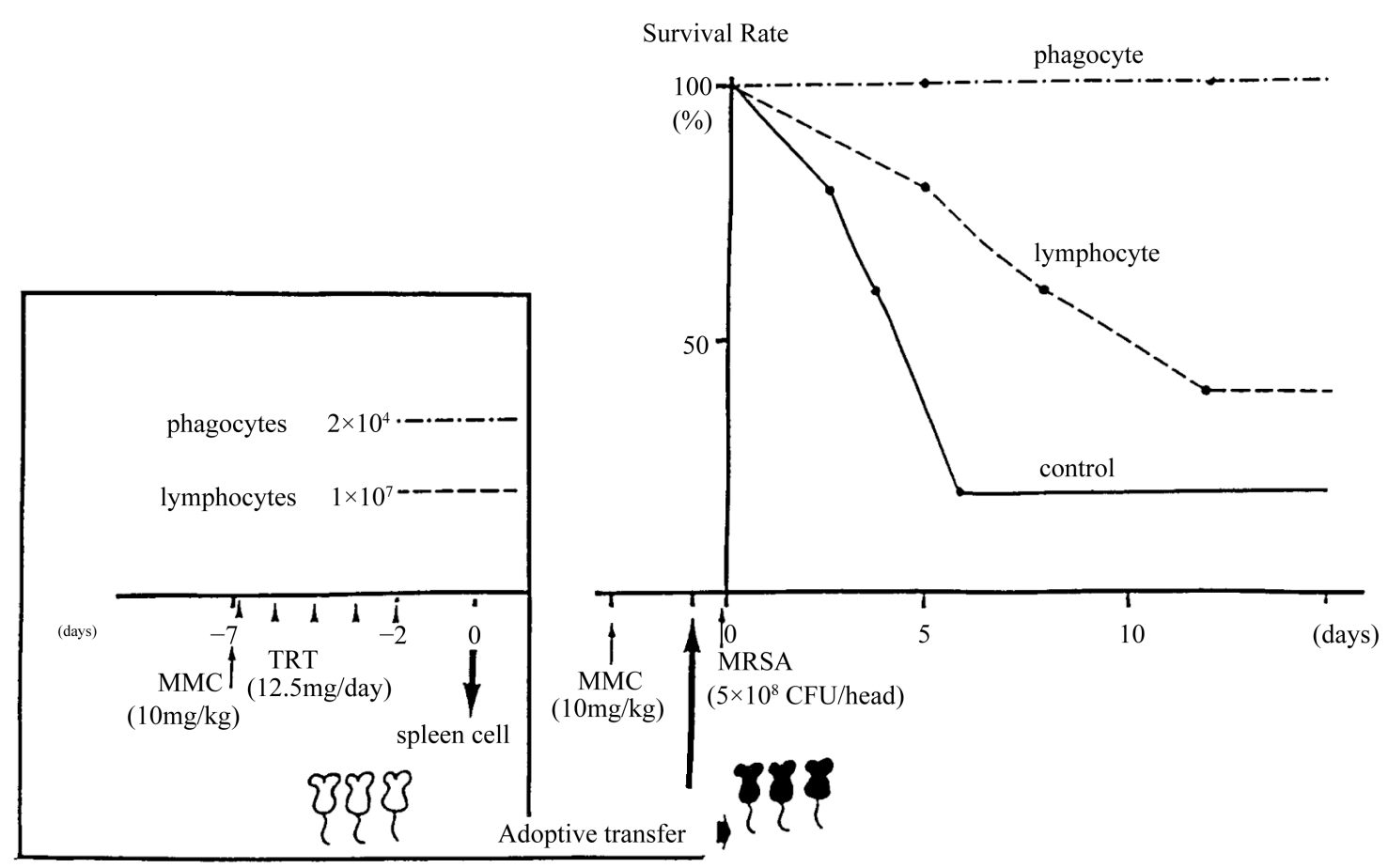

Figure 8. The adoptive transfer of leukocyte sublet. The leukocyte from MMC treated and dLHT administered mice were separated granulocyte and lymphocyte. One week later, $5 \times 10^{5}$ MRSA were challenged and followed up their survival rate.

that of vancomycin group was 40\%, and that of dLHT and vancomycin-combined group was $80 \%$ (Figure 8). All of dLHT administered MMC-treated mice, to which the phagocytic cells prepared from MMC-treated mice with dLHT administration had adoptively been transferred, survived after the MRSA challenge. On the other hand, the survival rate of MMC-treated mice, to which the lymphocytes prepared from the same mice had adoptively been transferred, was $40 \%$ (Figure 8 ).

\section{Clinical Trial in Infection Control in Bed Side}

Six patients were recruited for this trial. They were inpatient in substantially infection control bed from outpatient for their nosocomial infection by MRSA. The original focuses were atrial attack and cerebral bleeding by hypertension and low value of serum albumin. Two of the same type of patients attended as control for the disagreement by their family. There were no new antibiotics in the commercial base for hospital, selecting the augmentation of host defense immunity. We selected four candidate herbalmedicines that augment blood cells in number and functions in previous studies. Based on the research in the MMC-generated immunocompromised host, dHLT is the best herbal medicine for both augmentation of host immune factors and increased sensitivity of MRSA to antibiotics. All four cases with dLHT treatment showed culture results of MRSA negative after the dLHT administration. The MRSA culture became negative within 50 days after the initial administration in four of the six subjects (Figure 9). In the control group, one case needed more than 100 days to become MRSAnegative and another died from the infection (Figure 10). One representative case is a 78-year-old woman suffering from hypertension, atrial fibrillation, and cerebral bleeding in the right occipital lobe. During the antibiotic therapy for Streptococcus pneumoniae, MRSA appeared. The antibiotic therapy was halted and the dLHT administration started. The culture result became negative in three weeks after the dLHT treatment. In addition, serum protein and albumin values also returned to the values that they had had before the infection of MRSA (Figure 9 and Figure 10).

\section{Discussion}

When dLHT was administered orally in mouse models whose immunopotential had been inhibited, the herbal 


\begin{tabular}{|c|c|c|c|c|c|c|c|c|c|c|}
\hline & 0 & 4 & 8 & 15 & 26 & 33 & 40 & 47 & 54 & (days) \\
\hline \multicolumn{11}{|l|}{ Culture } \\
\hline St.pneumoniae & $(2+)$ & & & & & & & & & \\
\hline MRSA & & & & $2 \mathrm{col}$. & 3 col. & $(+)$ & $(+)$ & $(-)$ & $(-)$ & \\
\hline $\begin{array}{l}\text { Antibiotics } \\
\qquad \text { Piperacillin }\end{array}$ & & $4 \mathrm{~g} /$ day & $2 \mathrm{~g} /$ day & $\begin{array}{l}\text { Ampicillit } \\
750 \mathrm{mg} / \mathrm{da} \\
\text { (P.O.) }\end{array}$ & & & & & & \\
\hline Gentamicin & & & & & & & & & & \\
\hline Minocycline & & $40 \mathrm{mg} /$ day & & $200 \mathrm{~m}$ & day & & & & & \\
\hline dLHT & & & & & & & & & & \\
\hline \multicolumn{11}{|l|}{ Laboratory Data } \\
\hline WBC & 13.4 & 5.3 & 4.7 & 9.4 & 5.3 & 6.0 & 5.9 & 5.1 & 6.0 & \\
\hline Leukocyte & 11.9 & 2.6 & 2.0 & 7.2 & 2.7 & 3.5 & 4.1 & 3.8 & 3.5 & \\
\hline Lymphocyte & 1.1 & 1.8 & 1.9 & 1.3 & 1.6 & 1.9 & 1.1 & 1.5 & 1.8 & $\left(\times 10^{3} / \mathrm{mm}\right)$ \\
\hline $\begin{array}{l}\text { CRP } \\
\text { temperature }\end{array}$ & $\begin{array}{c}6+ \\
37.5\end{array}$ & $2+$ & \pm & $\begin{array}{c}(-) \\
37.2\end{array}$ & $3+$ & $(-)$ & $(-)$ & $(-)$ & $(-)$ & $\left({ }^{\circ} \mathrm{C}\right)$ \\
\hline $\mathrm{TSP}(\mathrm{g} / \mathrm{dl})$ & 5.9 & & & & 5.0 & 5.5 & & 5.9 & & \\
\hline Alb.(g/dl) & 3.45 & & & & 2.85 & 3.27 & & 3.7 & & \\
\hline OKT4(\%;CD4) & & & & 41.5 & & & & & 55.0 & \\
\hline OKT $8(\% ; C D 8)$ & & & & 20. & & & & & 21.3 & \\
\hline
\end{tabular}

Figure 9. Human bed side test. The trial was done for stroke and/or heart infarction patient after informed and consented. Trial schedule and chemical data were show in the figure. The herbal decoction, $8 \mathrm{~g} /$ head of dLHT was administered daily for at least one month. Then MRSA were chased by collecting sputa from the patient. The blood chemical data were shown in the figure.

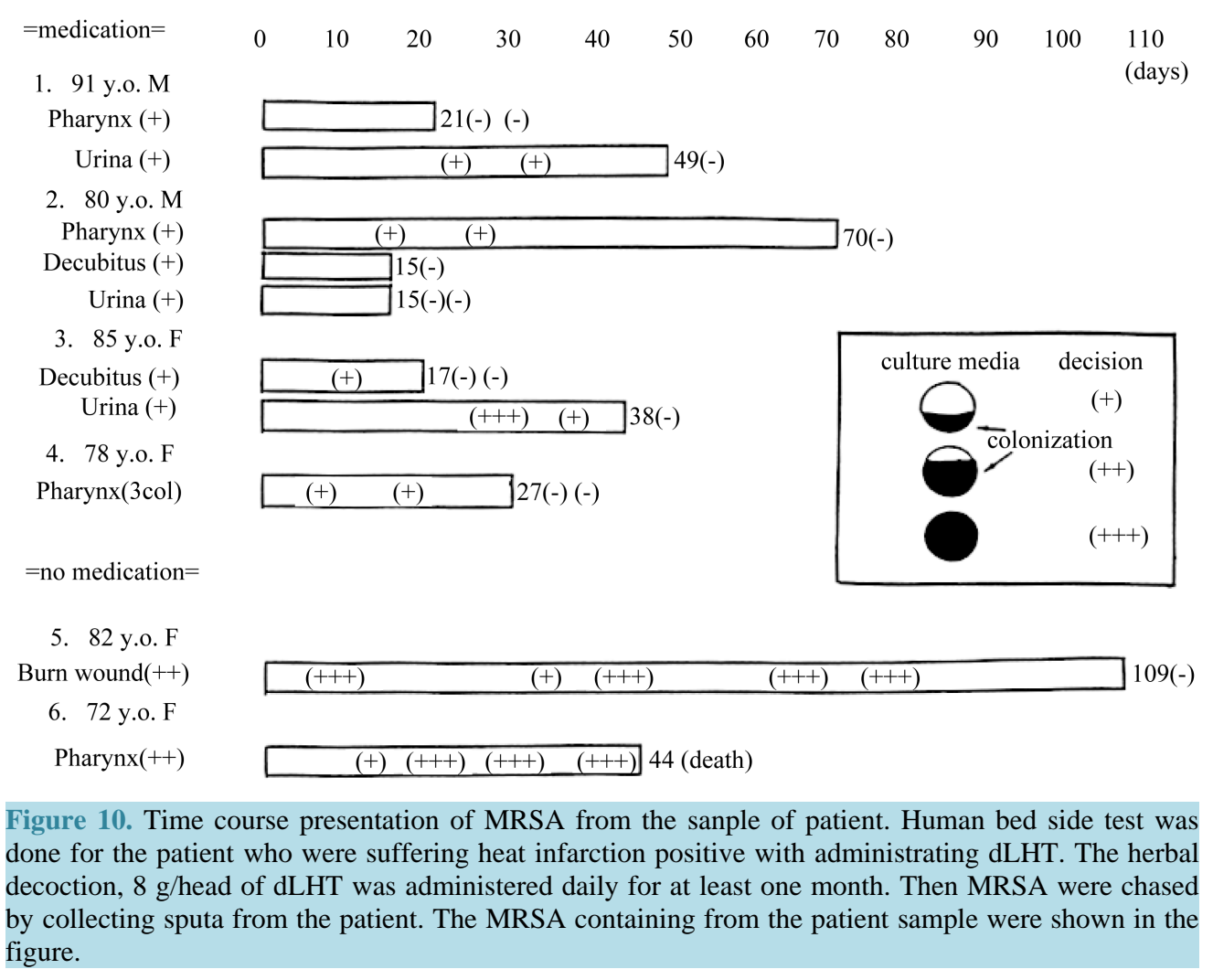


medicine activated the phagocytes both quantitatively and qualitatively, indicating dLHT to be an effective interstitial medicine [29]-[34]. In addition, based on the data from both the animal models and the clinical trial, no side effects were observed, confirming the complete efficacy of the drug. Of late, as we move towards a society with a high percentage of elderly people, the authors speculate that this Chinese herbal medicine which activates the immunopotential would be very helpful in the treatment of opportunistic infections that are commonly seen among the elder patients in the developed countries [35]-[40].

At the time of this clinical trial, vancomycin was not commercially available, so there were no suitable antibiotics for MRSA patients. Thereafter, vancomysin was purchased from markets with governmental approval. However, bacteria which are resistant against new drug might emerge after several years' use. So the trial to host immune defense enhanced by herbal decoction is important for infections of microorganisms.

This study selected dLHT because this formula was composed of several single herbs, which possessed the effects of augmentation of blood cell number and function. In a famous China textbook for herbal formulae in Qin Dynasty, the only descriptive is found stating that dLHT is effective for fever. Therefore, this formula is minor, not listed up in Japanese authorized herbal formulae for government.

From a pharmaceutical stand point of view, dLHT is composed with several anti-septic harbs, supposing the effect of dLHT for infection came from anti-septic effect. So we tried to compare dLHT, BYT and SDT against clinical derived MRSA in vitro agar plate. However, dLHT was not significantly effective for direct anti-septic effect for MRSA. So we conclude our result that, dLHT affects host immune activity especially for macrophage phagocytosis for this MRSA infection system.

In a simultaneous report, we tried to identify some herbal formulae which could augment blood cells in number and function in Shi-Quan-Da-Bu-Tang and Bu-Zong-Ye-Qi-Tang. dLHT exhibited has a similar character with Shi-Quan-Da-Bu-Tang, which also augments granulocyte/phagocyte.

Abo pointed out that he could differentiate granulocyte rich type from lymphocyte rich type according to the constitution. He reported that gentleman sorted out for G-rich type; on the other hand, ladies are lymphocyte rich type in the same. Within the gentleman G-rich type turned to L-rich-type at the senile. So in general, young people are recommended to employ Bu-Zong-Ye-Qi-Tang. On the other hand, senile is good for Shi-QuanDa-Bu-Tang [36]-[41].

\section{References}

[1] Kurashige, S., Yoshida, T. and Mitsuhashi, S. (1980) Immune Responsein Sarcoma 10-Bearing Mice. Annual Report of Gunnma University, 1, 36-44.

[2] Miyazaki, S. (1977) Immunodificiency in Clinical Origin. Clinical Pediatrics, 1001-1006.

[3] Kishida, K., Miyazaku, S., Take, H., Fujimoto, T., Shi, H., Sasaki, K. and Goya, N. (1978) Granial Irradiation and Lymphocyte Subpopulation in Acute Lymphatic Leukemia. Journal of Pediatrics, 92, 785-786. http://dx.doi.org/10.1016/S0022-3476(78)80155-3

[4] Yamaguchi, N., Takei, T., Chen, R., Wushuer, P. and Wu, W.H. (2013) Maternal Bias of Immunity to Her Offspring: Possibility of an Autoimmunity Twist out from Maternal Immunity to Her Young. Open Journal of Rheumatology and Autoimmune Diseases, 3, 40-55. http://dx.doi.org/10.4236/ojra.2013.31008

[5] Murgita, R.A. and Tomasi Jr., T.B. (1975) Suppression of the Immune Response by Alpha-Fetoprotein. The Journal of Experimental Medicine, 141, 269-286. http://dx.doi.org/10.1084/jem.141.2.269

[6] Paul, G., Margaret, S., Liew, Y.F. and Allan, M.M. (1995) CD4+ but Not CD8+ T Cells Are Required for the Induction of Oral Tolerance. International Immunology, 7, 501-504. http://dx.doi.org/10.1093/intimm/7.3.501

[7] Koshimo, H., Miyazawa, H.Y., Shimizu, Y. and Yamaguchi, N. (1989) Maternal Antigenic Stimulation Actively Produces Suppressor Activity in Offspring. Developmental \& Comparative Immunology, 13, 79-85. http://dx.doi.org/10.1016/0145-305X(89)90020-7

[8] Zoeller, M. (1988) Tolerization during Pregnancy: Impact on the Development of Antigen-Specific Help and Suppression. European Journal of Immunology, 18, 1937-1943. http://dx.doi.org/10.1002/eji.1830181211

[9] Shinka, S., Dohi, Y., Komatsu, T., Natarajan, R. and Amano, T. (1974) Immunological Unresponsiveness in Mice. I. Immunological Unresponsiveness Induced in Embryonic Mice by Maternofetal Transfer of Human-Globulin. Biken Journal, 17, 59-72.

[10] Aase, J.M., Noren, G.R., D.V. Reddy, and Geme Jr., J.W. (1972) Mumps-Virus Infection in Pregnant Women and the Immunologic Response of Their Offspring. The New England Journal of Medicine, 286, 1379-1382. http://dx.doi.org/10.1056/NEJM197206292862603 
[11] Wang, X.X., Kitada, Y., Matsui, K., Ohkawa, S., Sugiyama, T., Kohno, H., Shimizu, S., Lai, J.E., Matsuno, H. and Yamaguchi, N. (1999) Variation of Cell Populations Taking Charge of Immunity in Human Peripheral Blood Following Hot Spring Hydrotherapy Quantitative Discussion. The Journal of Japanese Association of Physical Medicine, Balneology and Climatology, 62, 129-134.

[12] Matsuno, H., Wang, X.X., Wan, W., Matsui, K., Okawa, S., Sugiyama, T., Kohno, H., Shimizu, S., Lai, J.E. and Yamaguchi, N. (1999) Variation of Cell Populations Taking Charge of Immunity in Human Peripheral Blood Following Hot Spring Hydrotherapy Qualitative Discussion. The Journal of Japanese Association of Physical Medicine, Balneology and Climatology, 62, 135-140.

[13] Yamaguchi, N., Hashimoto, H., Arai, M., Takada, S., Kawada, N., Taru, A., Li, A.L., Izumi, H. and Sugiyama, K. (2002) Effect of Acupuncture on Leukocyte and Lymphocyte Subpopulation in Human Peripheral Blood-Quantitative Discussion. The Journal of Japanese Association of Physical Medicine, Balneology and Climatology, 65, 199-206.

[14] Wan, W., Li, A.L., Izumi, H., Kawada, N., Arai, M., Takada, A., Taru, A., Hashimoto, H. and Yamaguchi, N. (2002) Effect of Acupuncture on Leukocyte and Lymphocyte Subpopulation in Human Peripheral Blood Qualitative Discussion. The Journal of Japanese Association of Physical Medicine, Balneology and Climatology, 65, 207-211.

[15] Wang, X.X., Katoh, S. and Liu, B.X. (1998) Effect of Physical Exercise on Leukocyte and Lymphocyte Subpopulations in Human Peripheral Blood. Cytometry Research, 8, 53-61.

[16] Kitada, Y., Wan, W., Matsui, K., Shimizu, S. and Yamaguchi, N. (2000) Regulation of Peripheral White Blood Cells in Numbers and Functions through Hot-Spring Bathing during a Short Term Studies in Control Experiments. Journal of the Japanese Society of Balneology, Climatology and Physical Medicine, 63, 151-164.

[17] Yamaguchi, N., Takahashi, T., Sugita, T., Ichikawa, K., Sakaihara, S., Kanda, T., Arai, M. and Kawakita, K. (2007) Acupuncture Regulates Leukocyte Subpopulations in Human Peripheral Blood. Evidence-Based Complementary and Alternative Medicine, 4, 447-453.

[18] Yamaguchi, N., Shimizu, S. and Izumi, H. (2004) Hydrotherapy Can Modulate Peripheral Leukocytes: An Approach to Alternative Medicine. In: Complementary and Alternative Approaches to Biomedicine, Kluwer Academic/Plenum Publishers, New York, 239-251. http://dx.doi.org/10.1007/978-1-4757-4820-8_18

[19] Gorantla, S., Dou, H., Boska, M., Destache, C.J., Nelson, J., Poluektova, L., Rabinow, B.E., Gendelman, H.E. and Mosley, R.L. (2006) Quantitative Magnetic Resonance and SPECT Imaging for Macrophage Tissue Migration and Nanoformulated Drug Delivery. Journal of Leukocyte Biology, 80, 1165-1174. http://dx.doi.org/10.1189/jlb.0206110

[20] Stoika, R.S., Lutsik, M.D., Barska, M.L., Tsyrulnyk, A.A. and Kashchak, N.I. (2002) In Vitro Studies of Activation of Phagocytic Cells by Bioactive Peptides. Journal of Physiology and Pharmacology, 53, 675-688.

[21] Elbim, C., Pillet, S., Prevost, M.H., Preira, A., Girard, P.M., Rogine, N., Hakim, J., Israel, N. and Gougerot-Pocidalo, M.A. (2001) The Role of Phagocytes in HIV-Related Oxidative Stress. Journal of Clinical Virology, 20, 99-109. http://dx.doi.org/10.1016/S1386-6532(00)00133-5

[22] Speer, C.P., Gahr, M. and Pabst, M.J. (1986) Phagocytosis-Associated Oxidative Metabolism in Human Milk Macrophages. Acta Paediatrica, 75, 444-451. http://dx.doi.org/10.1111/j.1651-2227.1986.tb10228.x

[23] Waitzberg, D.L., Bellinati-Pires, R., Salgado, M.M., Hypolito, I.P., Colleto, G.M., Yagi, O., Yamamuro, E.M., GamaRodrigues, J. and Pinotti, H.W. (1997) Effect of Total Parenteral Nutrition with Different Lipid Emulsions on Human Monocyte and Neutrophil Functions. Nutrition, 13, 128-132. http://dx.doi.org/10.1016/S0899-9007(96)00386-3

[24] Kaplan, S.S., Basford, R.E., Jeong, M.H. and Simmons, R.L. (1996) Biomaterial-Neutrophil Interactions: Dysregulation of Oxidative Functions of Fresh Neutrophils Induced by Prior Neutrophil-Biomaterial Interaction. Journal of Biomedical Materials Research, 30, 67-75. http://dx.doi.org/10.1002/(SICI)1097-4636(199601)30:1<67::AID-JBM9>3.0.CO;2-P

[25] Cohen, M.S., Britigan, B.E., Chai, Y.S., Pou, S., Roeder, T.L. and Rosen, G.M. (1991) Phagocyte-Derived Free Radicals Stimulated by Ingestion of Iron-Rich Staphylococcus aureus: A Spin-Trapping Study. Journal of Infectious Diseases, 163, 819-824. http://dx.doi.org/10.1093/infdis/163.4.819

[26] Mege, J.L., Martin, C., Saux, P., Charrel, J., Mallet, M.N. and Bongrand, P. (1989) Phagocyte-Pathogen in the Infected Host. Critical Care Medicine, 17, 1247-1253.

[27] Root, R.K., Rosenthal, A.S. and Balestra, D.J. (1972) Abnormal Bactericidal, Metabolic, and Lysosomal Functions of Chediak-Higashi Syndrome Leukocytes. Journal of Clinical Investigation, 51, 649-665. http://dx.doi.org/10.1172/JCI106854

[28] Jerne, N.K. and Nordin, A.A. (1963) Plaque Formation in Agar by Single Antibody Producing Cells. Science, 140, 405.

[29] Jerne, N.K., Nordin, A.A. and Henry, C. (1963) The Agar Technique for Recognizing Antibody Producing Cells. In: Amons, B. and Kaprowski, H., Eds., Cell-Bound Antibodies, The Wistar Institute Press, Philadelphia, 109-125.

[30] Shih, C.C., Liao, C.C., Su, Y.C., Tsai, C.C. and Lin, J.G. (2012) Gender Differences in Traditional Chinese Medicine 
Use among Adults in Taiwan. PLoS ONE, 7, e32540. http://dx.doi.org/10.1371/journal.pone.0032540

[31] Lin, M.H., Chou, M.Y., Liang, C.K., Peng, L.N. and Chen, L.K. (2010) Population Aging and Its Impacts: Strategies of the Health-Care System in Taipei. Ageing Research Reviews, 9, S23-S27. http://dx.doi.org/10.1016/j.arr.2010.07.004

[32] Lin, Y.H. and Chiu, J.H. (2011) Use of Chinese Medicine by Women with Breast Cancer: A Nationwide Cross-Sectional Study in Taiwan. Complementary Therapies in Medicine, 19, 137-143. http://dx.doi.org/10.1016/j.ctim.2011.04.001

[33] Navo, M.A., Phan, J., Vaughan, C., Lynn Palmer, J., Michaud, L., Jones, K.L., et al. (2004) An Assessment of the Utilization of Complementary and Alternative Medication in Women with Gynecologic or Breast Malignancies. Journal of Clinical Oncology, 22, 671-677.

[34] Liao, H.L., Ma, T.C., Chiu, Y.L., Chen, J.T. and Chang, Y.S. (2008) Factors Influencing the Purchasing Behavior of TCM Outpatients in Taiwan. Journal of Alternative and Complementary Medicine, 14, 741-748. http://dx.doi.org/10.1089/acm.2007.7111

[35] Liu, J.P., Yang, H., Xia, Y. and Cardini, F. (2009) Herbal Preparations for Uterine Fibroids. Cochrane Database of Systematic Reviews, 2009, Article ID: 005292. http://dx.doi.org/10.1002/14651858.CD005292.pub2

[36] Abo, T., Kawate, T., Itoh, K. and Kumagai, K. (1981) Studies on the Bioperiodicity of the Immune Response. 1. Circadian Rhythms of Human T, B and K Cell Traffic in the Peripheral Blood. Journal of Immunology, 126, 1360-1363.

[37] Abo, T. and Kumagai, T. (1978) Studies of Surface Immunoglobulins on Human B Lymphocytes. III. Physiological Variations of SIg ${ }^{+}$Cells in Peripheral Blood. Clinical \& Experimental Immunology, 33, 441-452.

[38] Suzuki, S., Toyabe, S., Moroda, T., Tada, T., Tsukahara, A., Iiai, T., et al. (1997) Circadian Rhythm of Leukocytes and Lymphocytes Subsets and Its Possible Correlation with the Function of the Autonomic Nervous System. Clinical \& Experimental Immunology, 110, 500-508. http://dx.doi.org/10.1046/j.1365-2249.1997.4411460.x

[39] Ignarro, L.J. and Colombo, C. (1973) Enzyme Release from Polymorphonuclear Leukocyte Lysosomes: Regulation by Autonomic Drugs and Cyclic Nucleotides. Science, 180, 1181-1183. http://dx.doi.org/10.1126/science.180.4091.1181

[40] Elenkov, I.J. and Crousos, G.P. (1999) Stress Hormones, Th1/Th2 Patterns, Pro/Anti-Inflammatory Cytokines and Susceptibility to Disease. Trends in Endocrinology and Metabolism, 10, 359-368.

[41] Landmann, R.M.A., Muller, F.B., Perini, C., Wesp, M., Erne, P. and Buhler, F.R. (1984) Changes of Immunoregulatory Cells Induced by Psychological and Physical Stress: Relationship to Plasma Catecholamines. Clinical \& Experimental Immunology, 58, 127-135.

\section{Abbreviations}

BYT: Bu-Zong-Ye-Qi-Tang. A famous TCM formula for augment blood cell in number and function.

CAM: Complementary and alternative medicine. Beside the western medicine, there are many traditional medicine and/or health promoting menu all over the world.

CD: Cluster of differentiation. Each lymphocyte has name that expressed CD number, for example CD2, CD4, etc.

PFC: Plague forming cell. Detecting method for antibody producing cell.

SRBC: Sheep red blood cell. Good T-dependent antigen for detecting PFC.

SPC: Spleen cell. Cells from central organ where antibody secreting cells develop.

SDT: Shi-Quan-Da-Bu-Tang. A famous TCM formula for augment blood cell in number and function. sCRT: Shao-Chin-Rong-Tang. A famous TCM formula for suppressed leukocyte in number and function. 